\title{
Temperature sensitivity and performance evaluation of asphalt cement incorporating different types of waste polymers
}

\author{
Mahmoud Enieb $^{a *}$ (D), Ahmed Salama Eltwati ${ }^{b}$ iD, Mohammed Abbas Al-Jumailic iD \\ aDepartment of Civil Engineering, Assiut University, Assiut, Egypt $\longrightarrow$ \\ ${ }^{\mathrm{b}}$ Department of Roads and Airports Engineering, Bright Star University, Brega, Libya $\mathrm{W}$ \\ 'Department of Civil Engineering, University of Kufa, Iraq $\mathrm{W}$
}

\author{
Highlights \\ - Temperature susceptibility of Asphalt cements modified \\ with $\mathrm{CR}$ and $\mathrm{rPET}$ was investigated \\ - The Temperature susceptibility was investigated by using PI, \\ PVN, VTS, and AE methods \\ - CR and rPET decreased the temperature susceptibility
}

- CR and rPET increased the high temperature performance

- Correlation between the methods used to evaluate the temperature sensitivity

$\mathrm{CR}$ and rPET improved the rheological characteristics

\begin{abstract}
There is significant evidence that utilizing polymers improves asphalt cement characteristics, preserve the environment, and increases industrial-economic benefits. Consequently, the use of such modifier in asphalt cements via sustainable technology is strongly encouraged. The major goal of this research is to study the effect of modified asphalt cement with crumb rubber (CR) $(10 \%, 15 \%$, and $20 \%$ CR) and recycled polyethylene terephthalate (rPET) $(1.5 \%$, and $2.5 \%$ rPET) on the physical and rheological characteristics of asphalt cements. Asphalt cement experiments such as softening point, penetration, and rotational viscosity (RV), were performed on both the virgin and modified asphalt cements. The effect of CR and rPET on the temperature sensitivity of the asphalt cement was also evaluated by checking the penetration index (PI), penetration viscosity number (PVN), viscosity-temperature sensitivity (VTS), activation energy flow methods (AE) of all the modified asphalt cements. The rutting index $\left(\mathrm{G}^{*} / \sin \delta\right)$ was calculated using Bari and Witczak model. The findings revealed that the addition of CR and rPET in the asphalt cement reduced the temperature sensitivity and enhanced the rheological characteristics of the asphalt cements. Moreover, incorporating the CR and rPET into virgin asphalt cements increased the high temperature performance of all percentage of CR and $2.5 \%$ WP modified asphalt. There was a considerable correlation between temperature sensitivity methods; PI, PVN, VTS, and AE. Finally, virgin asphalt modified with $\mathrm{CR}$ is better than $\mathrm{PPET}$.
\end{abstract}

Information
Received:
Received in revised:
10.12 .2021
Accepted:

20.12.2021

Keywords: Crumb rubber (CR), High temperature performance grading, Polyethylene terephthalate (PET), Rheological-physical properties, Temperature sensitivity

\section{Introduction}

Asphalt cements are viscoelastic materials, which are a tough elastic at temperatures that are low and a viscous liquid at high temperatures. Pavement performance is intimately related to the viscoelastic characteristics of asphalt cements and is gradually deteriorated when there is a heavy traffic volume and high-temperatures. In general, the loading period and temperature have a negative effect on the properties of asphalt cements [1, 2]. Hence, it is necessary to characterize asphalt cements with the aim of estimating the influences of temperature and stress on important engineering parameters. The behavior of asphalt pavements exhibits extreme sensitivity to temperature, including permanent high temperature deformation, service temperature fatigue, and thermal cracking due to low temperature [3, 4]. Temperature sensitivity is a significant factor in terms of rheological characteristics of asphalt cements. The term "temperature susceptibility" refers to a variation in the consistency of the asphalt cement $s$ as a function of temperature. However, asphalt cements that have been modified to enhance the characteristics and function of the asphalt mixture is a viable approach to overcome the

*Corresponding author: m.enieb@aun.edu.eg (M. Enieb, +201002878440)

https://doi.org/10.53635/jit.984159

This work is licensed under CC BY 4.0 (C) (1) 
problems of asphalt cements arising from their tendency to degrade performance against temperature.

Polymer modifications are a common technology to improve the quality of asphalt cements, which have an effect on asphalt pavement permeant deformation and thermal cracking. It is commonly recognized that polymer additives tend to enhance the characteristics of the asphalt cements considerably [5-8]. Polymers, for example, enhance cohesion, elasticity, and temperature sensitivity of asphalt cements, improve durability, low temperature thermal cracking, and high temperatures rutting in asphalt concretes concretes [9-13]. The polymers that are utilized as asphalt cement modifiers comprise three groups of plastomers, elastomer, and reactivity, depending to their composition and chemical properties. Although polymer modifiers reduce asphalt cements' thermal sensitivity, each kind of polymer has a different effect on the characteristics of asphalt cements [14]. Reactive and plastomer polymers generally raise stiffness and rutting resistance, while elastomer polymers enhance the elastic characteristics (fatigue resistance) of bitumen asphalt cements [15, 16]. Polyethylene, ethylene-butyl acrylate (EBA), and ethylene-vinyl acetate (EVA) copolymers are the most commonly used plastomers in the manufacturing of asphalt mixes, whereas styrene-butadiene natural rubber (SBR) is the most commonly used elastomer in the pavement industry.

Rubber and elastomer materials have been widely used for a long time as asphalt cement's modifiers and have received considerable attention from asphalt scientists due to their suitable properties, which have the ability to enhance various aspects of the asphalt cements and mixtures [17-20]. Furthermore, as a result of the environmental demand to reuse waste products, the utilization of rubber materials in asphalt mixtures offers alternative or more engineering application than recovered scrap tires. Elastomer's polymer additives such as styrene-butadiene rubber (SBR) and reclaimed polymers for instance crumb rubber (CR) have been applied to improve the temperature sensitivity of asphalt cements [21-24]. The combination of SBR with an asphalt cement results in the formation of a Split-phase block copolymer that absorbs oil and swells up to 9 times its original volume [25]. This leads to a significant variation in the characteristics of the original asphalt cement. The rheological behavior of asphalt cements containing SBR and CR has been evaluated by several studies [26-31]. They found that the inclusion of SBR and CR increased the fatigue life of the base asphalt cements. Furthermore, the performance of asphalt pavements such as rutting properties, resilient modulus, and tensile strength, were improved.

The global use of plastics is increasing substantially above the recycling rate, and the need for recycled materials is developing. The use of waste materials from recycled plastics in asphalt mixtures is being recognized as a practical approach to producing polymer modified asphalt to replace chemically pure virgin polymers and to provide environmental and economic benefits [32, 33]. As a result of the demand for recycling with the support of several governments, studies on recycled plastics in asphalt have increased dramatically in recent years. Joohari and Giustozzi, [34] investigated the commercial plastomers i.e., ethylene vinyl acetate (EVA), low density polyethylene (LDPE) and linear low-density polyethylene (LLDPE) as asphalt cements' modifiers. It was found that modification of asphalt cements enhanced stiffness at high temperatures and increased elasticity at moderate temperature. It was also shown that the incorporation of the plastomer into the asphalt cements led to an increase in stiffness and elastic behaviors at high temperatures and viscosity at low-temperatures. Bensaada et al., [35] found that modifying the asphalt cement with $3 \%$ waste plastics increased the softening point and decreased penetration. Furthermore, at superior temperatures, the rheological properties of asphalt cements were enhanced, resulting in a decrease in kinetic sensitivity and an enhancement in rutting resistance.

\section{Objectives}

The purpose of this study was to investigate how modifiers i.e., CR derived from scrap tires and recycled polyethylene terephthalate ( $\mathrm{rPET}$ ) produced from waste plastic cups (WP) affect the characteristics and temperature sensitivity of asphalt cements. To accomplish this, the rheological and physical characteristics of CR and WP modified-asphalt cements were assessed via the softening point test (SP), penetration test (Pen), and rotational viscometer (RV). Temperature susceptibility of the modified asphalt cements was measured using various methods in this study, including penetration index (PI), penetration viscosity number (PVN), viscosity-temperature susceptibility (VTS), activation energy flow methods (AE), rutting index $\left(\mathrm{G}^{*} / \sin \delta\right)$ for unaged asphalt cement using Bari and Witczak models [36].

\section{Materials}

The important steps that have been undertaken in this study are shown in Figure 1. Base asphalt cement was used, which was supplied from a nearby petroleum refinery and had PG 64-16. Table 1 represents the characteristics of the base asphalt cement utilized in this research. In this work, shredded waste plastic water cup (WP) and crumb tire rubber (CR) were utilized as asphalt cement modifications to improve the temperature susceptibility of asphalt cements, as shown in Figure 2. The WP was extracted from the waste plastic cup with particle size ranging from 2- to 5- $\mathrm{mm}$ length and 0.4- $\mathrm{mm}$ width, sourced from a cup-making company. The main constitute of WP is rPET polymers and Table 2 reveals 
their physical properties. On the other side, the CR in fine particles forming with a maximum particle size of $300 \mu \mathrm{m}$ (passing sieve No. 50), was derived from scrap tires. Table 3 illustrates the properties of the CR.

Several samples were prepared to investigate the quality of modified asphalt cements in terms of temperature susceptibility. The first group of samples was made from modified base asphalt cement with $\mathrm{CR}$ in various amounts; $10 \%, 15 \%$, and $20 \%$ by the weight of asphalt cement. The other group of samples was rPET incorporated to the base asphalt cement with percentages of $1.5 \%$ and $2.5 \%$, by weight of the asphalt cement. All modified asphalt cements were made with high-speed shear blender (5000 r/minute) for one hour and the modification was constantly stirred at a temperature of $180{ }^{\circ} \mathrm{C}$ for 20 minutes at $1000 \mathrm{r} /$ minutes to reduced bubbles [2].

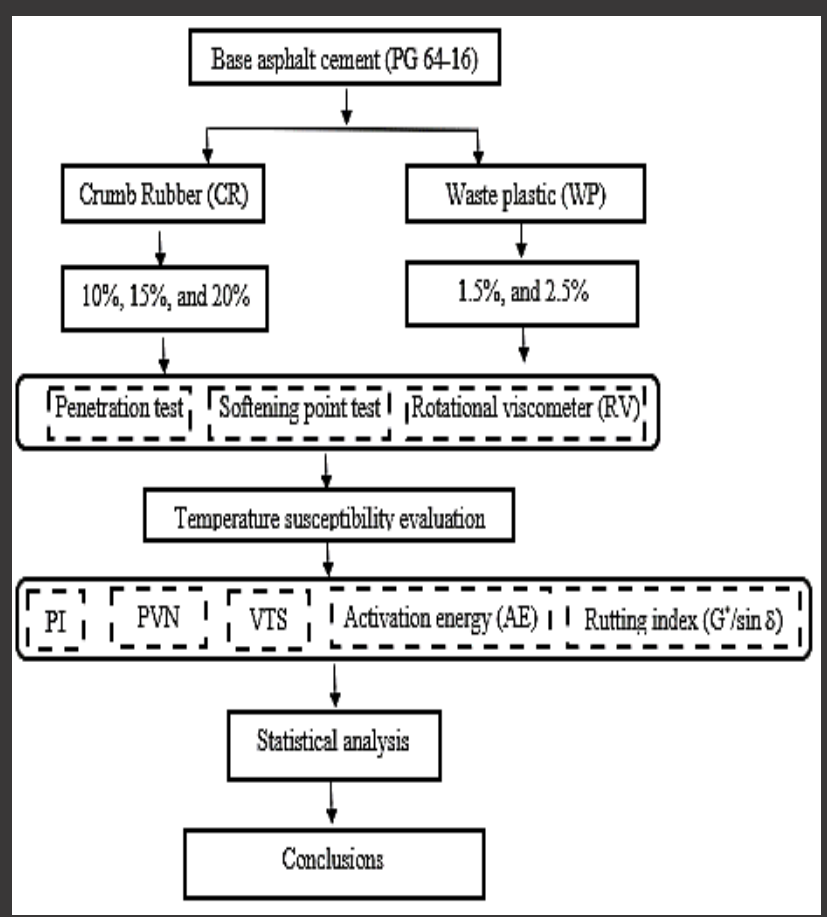

Figure 1. Experimental flowchart

Table 1. Base asphalt cement properties (PG 64-16).

\begin{tabular}{lll}
\hline Property & Value & Standards \\
\hline \hline RV @135 ${ }^{\circ} \mathrm{C}, \mathrm{cP}$ & 814 & ASTM D 4402 \\
RV @150 ${ }^{\circ} \mathrm{C}, \mathrm{cP}$ & 275 & - \\
$\mathrm{RV} @ 165{ }^{\circ} \mathrm{C}, \mathrm{cP}$ & 150 & - \\
Penetration @2 $5^{\circ} \mathrm{C}, 5 \mathrm{~s},(0.1 \mathrm{~mm})$ & 46 & ASTM D5 \\
Softening point $\left({ }^{\circ} \mathrm{C}\right)$ & 52 & ASTM D 36 \\
Flash point $\left({ }^{\circ} \mathrm{C}\right)$ & 305 & ASTM D 92 \\
Specific gravity & 1.13 & ASTM D 70 \\
Penetration indicator (PI) & -0.91 & - \\
Penetration viscosity number & -0.59 & - \\
(PVN) & &
\end{tabular}

Table 2. Characteristics of waste plastic (WP).

\begin{tabular}{ll}
\hline \hline Properties & Values \\
\hline \hline Density, g/cm ${ }^{3}$ & 0.91 \\
Tensile-strength, $\mathrm{MPa}$ & 8.7 \\
Tensile-elongation $(\%)$ & 355 \\
Melting temperature $\left({ }^{\circ} \mathrm{C}\right)$ & 109 \\
Flexural modulus $(\mathrm{MPa})$ & 7.6 \\
\hline \hline
\end{tabular}

Table 3. Properties of crumb rubber (CR).

\begin{tabular}{lll}
\hline \hline Property & Value & Standards \\
\hline \hline Specific gravity & $\begin{array}{l}0.88 \\
1.5-2.5 \\
\text { (uncompacted) }\end{array}$ & ASTM D6270-98 \\
& $\begin{array}{l}1.2-0.9 \\
\text { (compacted) }\end{array}$ & \\
Void ratio, e & $1240-5173$ & ASTM D6270-98 \\
$\begin{array}{l}\text { Young's modulus, E, } \\
\text { kPa }\end{array}$ & 0.5 & - \\
$\begin{array}{l}\text { Poisson's ratio, }(\mu) \\
\text { Capacity of water } \\
\text { absorption (\%) }\end{array}$ & $2-4$ & - \\
Density (g/cm3) & 1.3 & - \\
\hline \hline
\end{tabular}

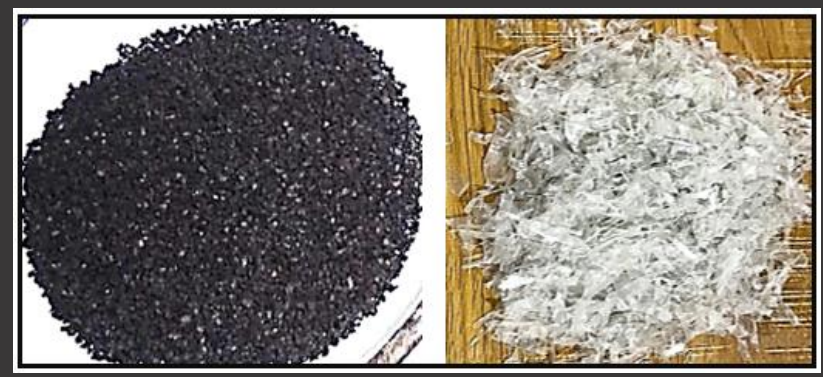

(a)

(b)

Figure.2. Materials used in this study, (a) crumb rubber (b) shredded plastic water cup.

\section{Methodology}

Several experimental tests i.e., the Pen, SP, and RV, were conducted in the laboratory to study rheological and physical characteristics of virgin and modified asphalt cements. ASTM-D36 [37] was used for the SP testing. The ring and ball device was employed to measure the softening point of asphalt cements which is explained as the temperature at which the asphalt cement must be heated for different road applications. Further, the penetration test at $25{ }^{\circ} \mathrm{C}$ was performed according to ASTM-D5 [38] standards, for consistency of asphalt cements measurement. The RV tester has been utilized to measure the viscosity of asphalt cements in the production and construction high temperature. RV testing ensures that the asphalt cement is a suitable temperature for mixing and compaction. According to the ASTM-D4402 [39] specification, the viscosity of the asphalt cement shall be less than $3000 \mathrm{MPa}$ at $135^{\circ} \mathrm{C}$.

\section{Methods Used for Temperature Sensitivity Evaluation}

Temperature sensitivity is a significant rheological feature of asphalt cements which is related to the final deformation performance. Temperature susceptibility is 
described as a parameter for determining how quickly the temperature changes in the asphalt cement properties. Recently, several different methods have been used to assess the temperature sensitivity of pure and modified asphalt cements. In this study, the methods of PI, VTS, and flow activation energy ( $A E$ ) were utilized to evaluate the asphalt cement's performance in terms of their susceptibility to temperatures ranging from low to high temperatures.

\subsection{Penetration index (PI) method}

The PI method evaluates the temperature sensitivity of asphalt cements using data from penetration and SP tests. The PI can be utilized to quickly determine the temperature sensitivity of asphalt cements even if it is sometimes unsuitable with polymer modified asphalt cements. The Handbook of Shell Bitumen [40] provides a traditional method for calculating PI, as illustrated by the equation below

$\mathrm{PI}=\frac{1950-500.0 \times \log (\text { Pen })-20 \times \mathrm{S} P}{50.0 \times \log (\text { Pen })-S \mathrm{P}-120.0}$

Where;

Pen=penetration @ $25^{\circ} \mathrm{C}$,

$\mathrm{SP}=$ temperature of softening point.

Higher PI values are the better performance in terms of temperature sensitivity of asphalt cements. Asphalt cements with an IP smaller than two for instance are extremely sensitive to temperature. It has been found that asphalt mixtures made of asphalt cements with low $\mathrm{PI}$ values are more susceptible to rutting and cracking at low temperatures $[41,42]$.

\subsection{Penetration viscosity number (PVN) method}

The PVN method is applied to estimate the temperature susceptibility of asphalt cements using the findings of penetration and viscosity tests. PVN was determined using the formula [43]:

$\mathrm{PVN}=1.50 \times\left(\frac{4.2580-0.79670 \times \log (\mathrm{Pen})-\log (\mathrm{RV})}{0.79510-0.18580 \times \log (\mathrm{Pen})}\right)$

Where;

Pen=penetration @ $25^{\circ} \mathrm{C}$ in deci-millimeters,

RV = viscosity @ $135^{\circ} \mathrm{C}$ in centistokes.

Asphalt cements usually have PVN values ranging from +0.5 to +2.0 [43]. The asphalt cement temperature sensitivity is higher with declining in the PVN value.

\subsection{Viscosity-temperature susceptibility (VTS) method}

The VTS process has been commonly utilized to estimate the susceptibility of an asphalt cement to temperatures. The following equation is usually used to calculate VTS [44]

$\log [\log (\eta)]=V T S \times \log (T)+A$

Where;

$\eta=$ viscosity in centipoise,

$\mathrm{T}=$ temperature of asphalt cement in degrees Rankine $\left(R^{\circ}\right)$,

$A=$ intercept,

VTS $=$ slope

\subsection{Activation energy of flow (AE) method}

Viscosity may also be used to determine the fluid's shear resistance to a stream. As the temperature rises, the thermal energy of the particles increases, decreasing the flow resistance and reducing the viscosity of the liquid. The $A E$, which acts as a boundary to viscous flow, must be achieved before flow can occur [45]. Equation (4), sometimes described as the "Arrhenius" formula, can be applied to predict the temperature-viscosity relationship with asphalt cements [46].

$\ln \eta=\frac{E_{f}}{R T}+\ln (A)$

Where;

$\eta=$ viscosity of asphalt cement in Pascal second, Pa.s

$A=$ regression constant,

$\mathrm{Ef}=$ activation energy, $\mathrm{kJ} / \mathrm{mol}$

$\mathrm{T}=$ temperature in degree $\mathrm{Kelvin},{ }^{\circ} \mathrm{K}$

$\mathrm{R}=$ universal constant of gas equal to $8.314 \mathrm{~J} / \mathrm{mol} /$ degree Kelvin

\subsection{Predict $\delta$ and $\mathbf{G}^{*}$ using Witczak models for base and modified asphalt cements}

Phase-angle $(\delta)$ and shear complex modulus (G*) are the two important parameters of Superpave determining viscoelastic behavior and finding performance grade (PG) of an asphalt cement. Bari and Witczak developed a model to predict with a high level of correlation $\left(R^{2}=0.99\right)$ to calculate $\mathrm{G}^{*}$ and $\delta$ at a given frequency and temperature according to the viscosity-temperature relationship as shown in Equation (3). This equation has 
been modified to account for loading frequency (fs $=1.59$ $\mathrm{Hz})$ ) to find $\delta$ in degrees and $\mathrm{G}^{*}$ in $\mathrm{Pa}$.

$\log \left(\log \eta_{\mathrm{fs}, \mathrm{t}}\right)=\mathrm{A}^{\prime}+\operatorname{VTS} \log (\mathrm{T})$

$A^{\prime}=A\left(0.96990 \times f_{s}^{0.0257}\right)$

$V_{T S}^{\prime}=$ VTS $\left(0.96680 \times f_{S}^{0.0575}\right)$

$\delta=\left[\begin{array}{c}90.0+\left(-7.3146-2.6162 \text { VTS }^{\prime}\right) \log \left(f_{s} \times \eta_{f s, t}\right) \\ +\left(0.1124+0.2029 . \text { VTS }^{\prime}\right) \times\left(\log \left(f_{s} \times \eta_{f s, t}\right)\right)^{2}\end{array}\right]$

$\mathrm{G}^{*}=0.0051 \mathrm{f}_{\mathrm{s}} \times \eta_{\mathrm{fs}, \mathrm{t}} \times(\sin \delta)^{7.1542-0.4929 \mathrm{f}_{\mathrm{s}}+0.0211 \mathrm{f}_{\mathrm{s}}^{2}}$

Where;

$\eta_{\mathrm{fs}, \mathrm{t}}$ is rotational viscosity as a function of $\mathrm{f}_{\mathrm{s}}$, in $\mathrm{CP}$,

$A^{\prime}$ is modified $A$,

VTS' is modified VTS

\section{Results and Discussion}

\subsection{Influence of $C R$ and WP on the Physical Characteristics of Asphalt cements}

Table 4 demonstrates the influence of CR and WP additions on the physical characteristics of asphalt cements as measured by softening point (S. P.) and penetration tests. From the table, adding the CR and WP led to reduce and increase the penetration and S. P. of the modified asphalt cements, respectively. This pattern was maintained as the contents of the additives increased.

Table 4. The softening point and penetration for base and

\begin{tabular}{lll}
\hline \hline $\begin{array}{l}\text { Asphalt } \\
\text { cement type }\end{array}$ & $\begin{array}{l}\text { Penetration,5s, @25 } \\
(0.1 \mathrm{~mm})\end{array}$ & $\begin{array}{l}\text { Softening point } \\
\left({ }^{\circ} \mathrm{C}\right)\end{array}$ \\
\hline \hline Base & 46 & 52 \\
Base+10\%CR & 40 & 59 \\
Base+15\%CR & 37 & 63 \\
Base+20\%CR & 31 & 66 \\
Base+1.5\%WP & 41 & 58 \\
Base+2.5\%WP & 34 & 62 \\
\hline \hline
\end{tabular}

Figure 3 displays the influence of CR and WP on the RV of base and modified asphalt cements at different temperatures. Viscosity was determined at temperatures between $135{ }^{\circ} \mathrm{C}$ and $165^{\circ} \mathrm{C}$ for all specimens in this investigation. However, according to Figure 3, the RV of the asphalt cement raised with the increasing the content of the additive. The findings also indicated that the RV at $135{ }^{\circ} \mathrm{C}$ of the $20 \% \mathrm{CR}$-modified asphalt cement was about 2.5 times greater than the $1.5 \%$ and $2.5 \%$ WP-modified asphalt cements.

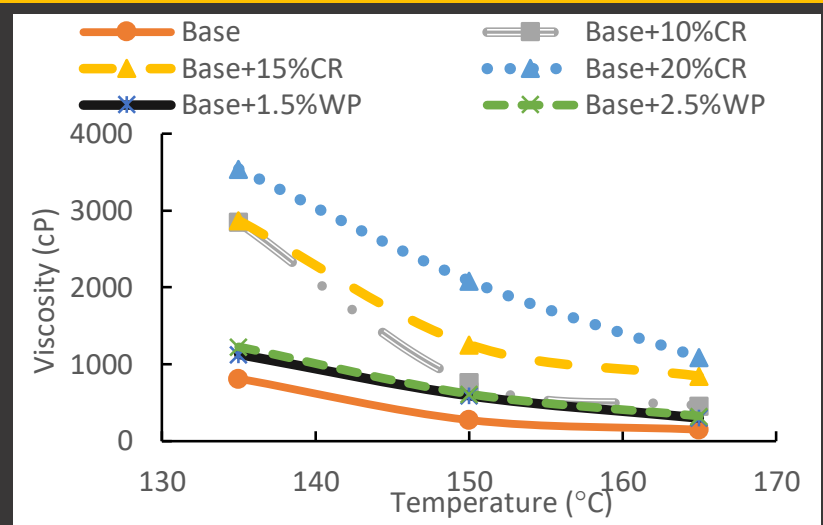

Figure. 3. Rotational viscosity of modified asphalt cements.

\subsection{Effect of WP and CR on the Temperature Susceptibility of Asphalt cements}

\subsubsection{Results of PI method}

Figure 4 illustrates the effect of incorporating crumb rubber and waste plastic on the penetration index (PI) of the reference and modified asphalt cements based on the penetration and softening point values. It was clear that the addition of waste plastics and crumb rubber enhanced the resistance to temperature susceptibility. This trend continued with the increase in the quantity of additives. Several previous studies showed the same results of this study $[47,48]$. The PI values for modified asphalt cements were within the acceptable range from 1.0 to +1.0 . Comparing $\mathrm{CR}$ with WP, the base asphalt cement (PG 64-16) with 20\% had the maximum, while the base asphalt cement with $1.5 \%$ contained the minimum $\mathrm{PI}$, respectively, indicating that CR-modified asphalt cements were less temperature susceptible than WPmodified asphalt cements. However, all the modified asphalt cements were shown to be less sensitive to changes in temperature compared to the base asphalt cement

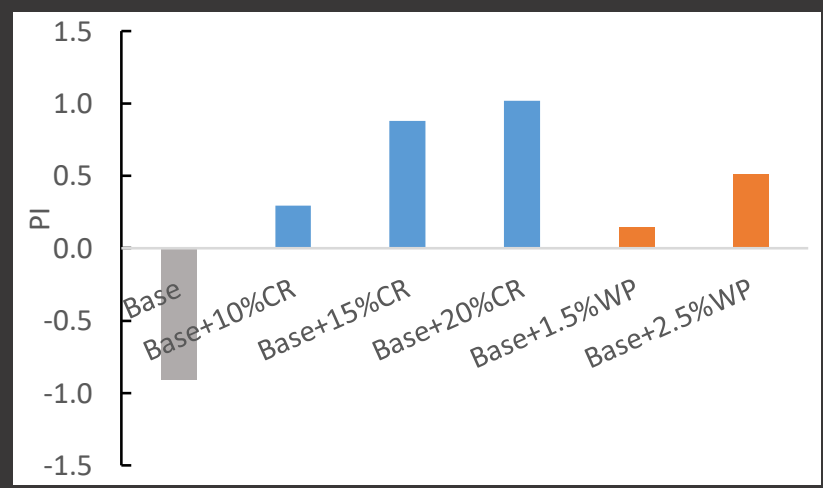

Figure 4. Results of PI for base and modified asphalt cements with $C R$ and WP.

\subsubsection{Results of PVN method}

The Penetration viscosity number (PVN) of the base and modified asphalt cement with CR and WP are shown in Figure 5. It was seen that increasing the contents of $C R$ and WP led to increase the VPN values, however, this was 
not always the case; for example, at $15 \% \mathrm{CR}$, there was a slight decrease in PVN. The figure also showed that all PVN values of asphalt cement specimens were in the +1.0 and -1.0 ranges. Typical PVN values for paving asphalt cements are in ranges of -0.5 to +2.0 and lower PVN values indicate higher temperature sensitivity, as said by Roberts, Kandhal [43]. Therefore, it can be concluded that the asphalt cement incorporating CR and WP had a lower susceptibility to the temperature than the base asphalt cement

\subsubsection{Results of VTS method}

Viscosity temperature sensitivity (VTS) was calculated to assess the temperature susceptibility at mixing and compaction temperatures $\left(135,150\right.$ and $\left.165^{\circ} \mathrm{C}\right)$. An increase in VTS values means that the asphalt cement is more sensitive to change with temperatures [44]. Figures 6 and 7 show the VTS values for the modified asphalt cements with various contents of CR and WP. As can be seen, increasing CR and WP contents contributed to lower the VTS values of asphalt cements. The Base $+20 \% C R$ provided the lowest value for the VTS, while the base asphalt cement exhibited the highest value. Therefore, the inclusion of CR and WP reduced the sensitivity of the modified asphalt cements to temperature variation.

\subsubsection{Results of AE method}

Figures 8 and 9 show the influence of CR and WP additives on the activation energy of the modified asphalt cement, and it was revealed that they were typically in the range of $58-70 \mathrm{~kJ} / \mathrm{mol}$ and $84 \mathrm{~kJ} / \mathrm{mol}$ for base asphalt cement. This results were consistent with findings of previous studies [46, 49]. It was also found that the asphalt cement containing CR and WP had a lower activation energy than the base asphalt cement, which means that the modified asphalt cements are less sensitive to change in temperature. This is due to the lower asphaltene content in the modified asphalt cement [50]. It was clear that as the CR percentages increased, the values of activation energy were reduced, indicating that asphalt cements with a greater concentration of CR were therefore less sensitive to the change in temperature. Conversely, increasing the WP content led to an increase in the activation energy.

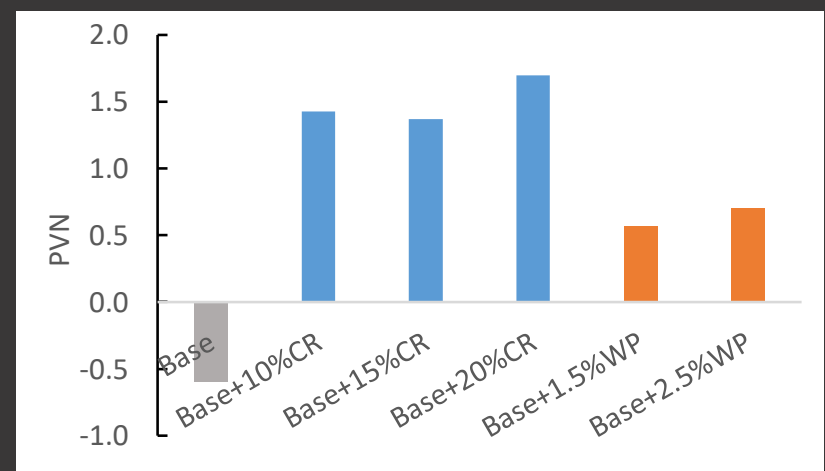

Figure 5. Results of PVN for the base and modified asphalt cements.

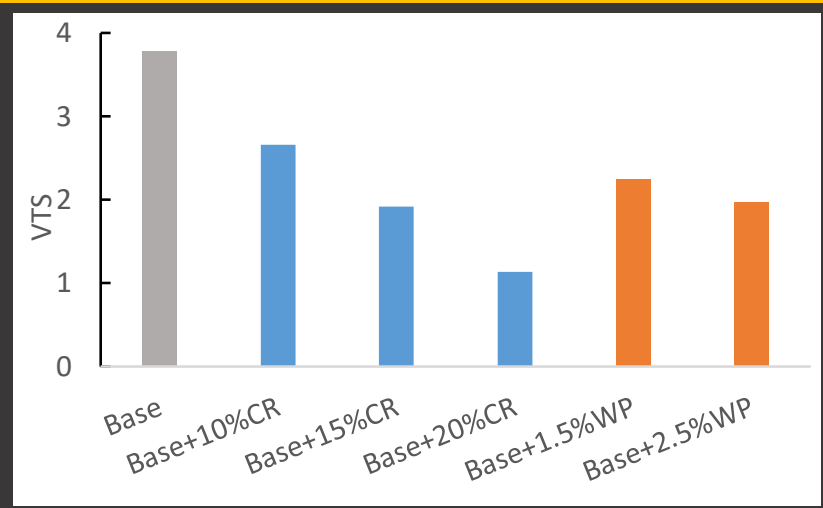

Figure 6. VTS results for modified and base asphalt cements @ 135,150 , and $165^{\circ} \mathrm{C}$.

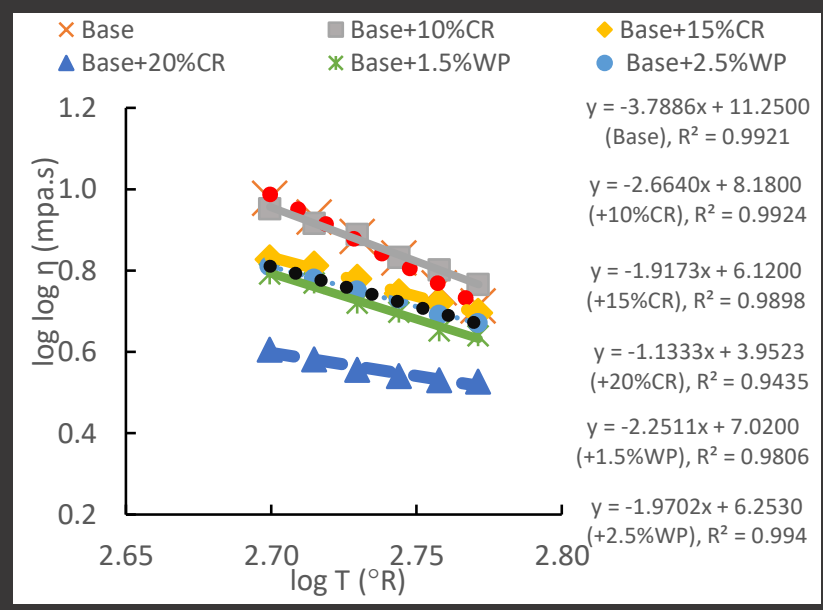

Figure 7. Viscosity-temperature relationship for the modified and base asphalt cements.

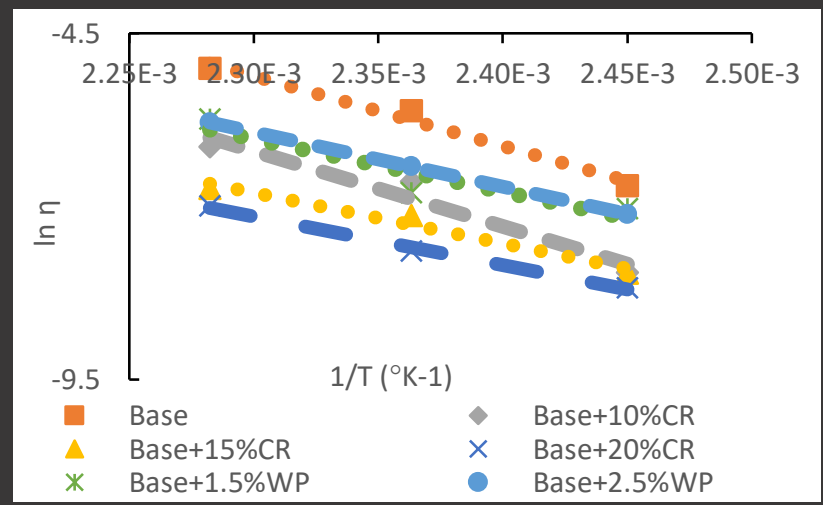

Figure 8 . Results of RV test for the modified and base asphalt cements.

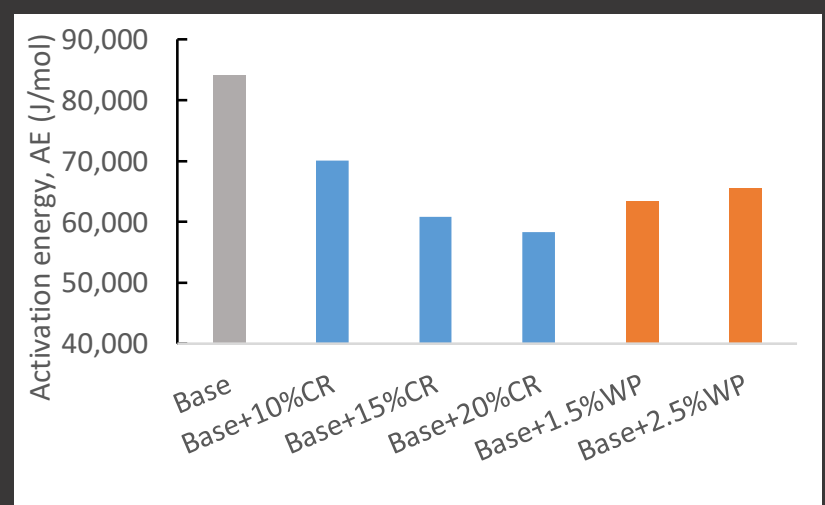

Figure 9. Results of $\mathrm{AE}$ for the modified and base asphalt cements. 
Table 5. Values of A and VTS for the base and modified asphalt cements

\begin{tabular}{lllllll}
\hline Asphalt & & Base+ & Base & Base & Base & Base \\
cement & Base & $10 \%$ & $+15 \%$ & + & + & + \\
types & & CR & CR & $\begin{array}{l}20 \% \\
\text { CR }\end{array}$ & $\begin{array}{l}1.5 \% \\
\text { WP }\end{array}$ & $\begin{array}{l}2.5 \% \\
\text { WP }\end{array}$ \\
\hline \hline VTS & -3.79 & -2.66 & -1.92 & -1.13 & -2.25 & -1.97 \\
A & 11.25 & 8.18 & 6.12 & 3.95 & 7.02 & 6.25 \\
\hline \hline
\end{tabular}

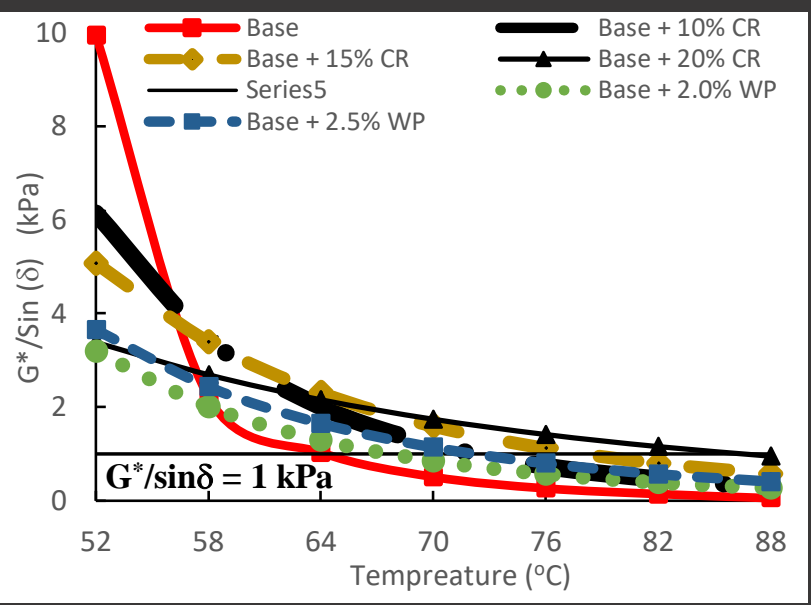

Figure 10. Results of performance grade at high temperature of base and modified asphalt cements.

\subsection{Effect of WP and $C R$ on the high-temperature performance grade}

From the results of Figure 6 and Equation 3, VTS is the slope of the regression and $A$ is the regression intercept of the linear logarithmic model of the relationship of temperature and viscosity shown in the following table for different asphalt cements. According to Bari and Witczak model with values of A and VTS from Table 5, Figure 10 is drawn from the range $(52-88)^{\circ} \mathrm{C}$.

Figure 10 shows the influences of WP and CR on the high temperature characteristics of asphalt cements. G* / Sin $(\delta)$ values for unaged asphalt cement must be $\geq 1.0 \mathrm{kPa}$ as per Superpave requirements to help avoid rutting failure. The base asphalt cement mixed with CR and WP increased the $\mathrm{G}^{*} / \mathrm{Sin}(\delta)$ as seen in Figure 10 . This means that the rutting resistance of modified asphalt cement was higher than the base asphalt cement. In addition, it can be observed that, with higher percentages of CR and WP, one can see that the pattern was still present. As can be seen, adding a CR of $20 \%, 15 \%$, and $10 \%$ to the base asphalt cement caused to upgrade the PG64-16 to PG82$x x, P G 76-x x$, and PG70-xx, respectively. A similar trend can be seen with WP modified asphalt cements, but with less significance; the base asphalt cement of PG 64-16 was affected by high temperature and 1.5\%WP and $2.5 \%$ modified asphalt cements have upgraded to PG 70-xx (with one-grade increase). Mirzaiyan, Ameri [25] also studied the effect of using elastomer polymer modifier on high-temperature-performance grading-modified asphalt cements, and their results support the findings of this study.
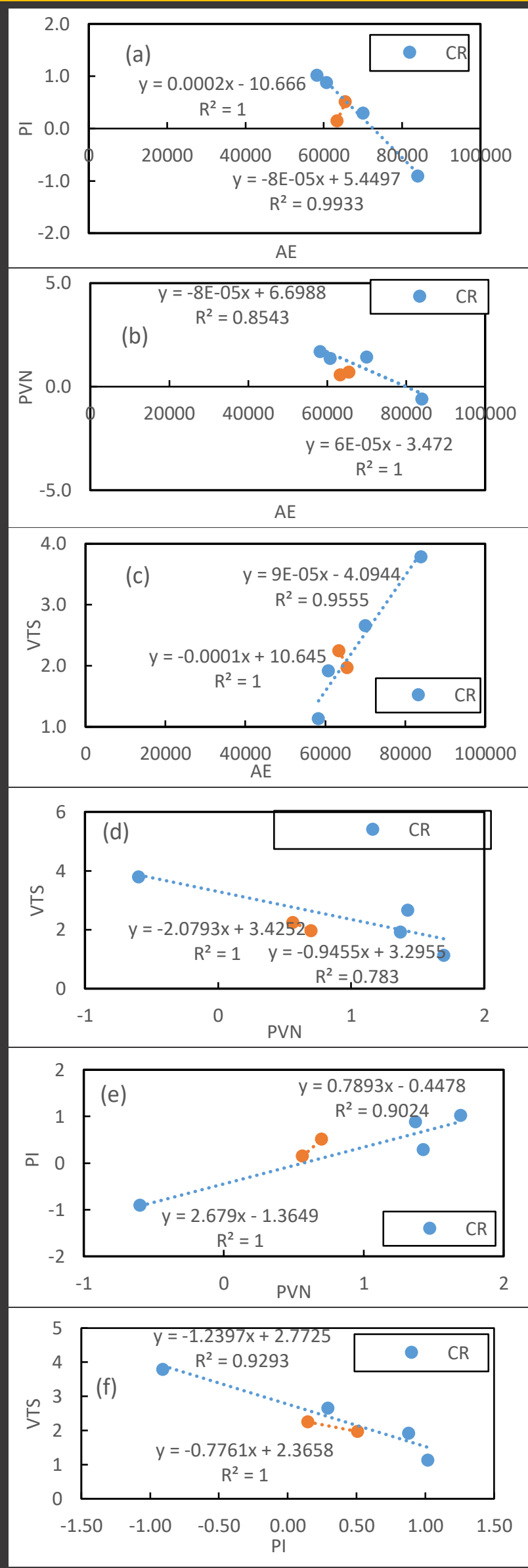

Figure 11. Correction between temperature susceptibility methods, (a) PI vs AE, (b) PVN vs AE, (c) VTS vs AE, (d) VTS vs PVN, (e) PI vs PVN, (f) VTS vs PI. 


\subsection{Correlation between the methods of temperature} susceptibility

This study used a variety of approaches to test the temperature susceptibility of modified asphalt cements, including PI, PVN, VTS, and AE methods. These methods showed different results and interpretations for temperature susceptibility; therefore, it is useful to conduct a statistical analysis to determine if there is a relationship between these methods. The correlation coefficient $(r)$ was used for the degree and strength of the correlation. The value of $r$ coefficient is in the range of 1.0 and +1.0 where the value is always absolute. The $r$ coefficient of 0 suggests that there is no connection between the variables being examined. The stronger the present correlation, regardless of direction, the closer the $r$ coefficient approaches1, suggesting a more linear relationship between the variables. The closer the coefficient $r$ towards \pm 1 , direction regardless, the stronger the correlation revealing a more linear relationship between the variables. Table 6 and Figure 11 show the correlations between temperature susceptibility methods; PI, PVN, VTS, and AE. The results showed that there was a significant correction among all methods, with the $r$ coefficient for all methods approaching \pm 1.0 , regardless of the waste polymer modifier types.

Table 6. Correlation coefficient of different methods of temperature susceptibility evaluation.

\begin{tabular}{l||cccc}
\hline \hline & AE & PVN & PI & VTS \\
\hline \hline AE & 1 & & & \\
PVN & -0.83 & 1 & & \\
PI & -0.95 & 0.92 & 1 & \\
VTS & 0.96 & -0.82 & -0.95 & 1 \\
\hline \hline
\end{tabular}

\section{Conclusion}

The following conclusion can be reached based on the experimental and theoretical findings of this study:

- The asphalt cement modified with CR and WP increased the softening point while penetration was reduced.

- The rotational viscosity of the modified asphalt cement was improved with increasing the additive content and was still less than $3000 \mathrm{cP}$ at $135{ }^{\circ} \mathrm{C}$ according to Superpave requirements. Also, the viscosity at $135{ }^{\circ} \mathrm{C}$ for the $20 \%$ CR modified asphalt cement was two and a half times greater than that of the $2.5 \%$ WP modified asphalt cement.

- The penetration index of $20 \%$ CR-modified asphalt cement was higher than $2.5 \%$ WP, which indicated that CR-modified asphalt cements were less sensitive to temperature than WP-modified asphalt cements.

- The penetration viscosity number (PVN) of CRmodified asphalt cements was higher than WPmodified asphalt cements. This shows that the CR- modified asphalt cement was less susceptible to temperature than WP-modified asphalt cement.

- The viscosity-to-temperature sensitivity (VTS) of asphalt cement modified with $20 \%$ CR is less than all percentage of WP-modified asphalt cements in absolute terms.

- The $15 \%$ and $20 \%$ CR modified asphalt cement had lower activation energy values than $1.5 \%$ and $2.5 \%$ WP-modified asphalt cements. This means that the CR-modified asphalt cement was less susceptible to temperature changes than the WP-modified asphalt cement.

- $20 \%$ CR-modified asphalt cement upgrade performance from PG64-xx to PG82-xx, while 2.5\% WP-modified asphalt cement and base asphalt cement have upgraded by one grade increment.

- There was a strong correlation coefficient among all methods of analysis. In conclusion, the CR-modified asphalt cement was better to the WP-modified asphalt cement

\section{Declaration of Interest Statement}

The authors declare that they have no known competing financial interests or personal relationships that could have appeared to influence the work reported in this paper.

\section{Author Contribution Statement}

M. Enieb: Conceptualization, Data Curation, Formal analysis, Investigation, Methodology, Resources, Software, Validation, Visualization, Writing - Original Draft, Writing - Review \& Editing - A. S. Eltwati: Conceptualization, Data Curation, Formal analysis, Investigation, Methodology, Resources, Software, Validation, Visualization, Writing - Original Draft, Writing - Review \& Editing - M. A. Al-Jumaili: Conceptualization, Data Curation, Formal analysis, Methodology, Project administration, Resources, Software, Supervision, Validation, Visualization.

\section{References}

[1] Ameri, M., Reza Seif, M., Abbasi, M., \& Khavandi Khiavi, A. (2017). Viscoelastic fatigue resistance of asphalt binders modified with crumb rubber and styrene butadiene polymer. Petroleum Science and Technology, 35(1), 30-36. https://doi.org/10.1080/10916466.2016.1233246

[2] Wang, W., Cheng, Y., Tan, G., Liu, Z., \& Shi, C. (2018). Laboratory investigation on high-and low-temperature performances of asphalt mastics modified by waste oil shale ash. Journal of Material Cycles and Waste Management, 20(3), 1710-1723. https://doi.org/10.1007/s10163-018-0737-2

[3] Barco Carrión, A. J. D., Lo Presti, D., Pouget, S., Airey, G., \& Chailleux, E. (2017). Linear viscoelastic properties of high reclaimed asphalt content mixes with biobinders. Road 
Materials and Pavement Design, 18(sup2), 241-251. https://doi.org/10.1080/14680629.2017.1304253

[4] Doll, B., Ozer, H., Rivera-Perez, J. J., Al-Qadi, I. L., \& Lambros, J. (2017). Investigation of viscoelastic fracture fields in asphalt mixtures using digital image correlation. International Journal of Fracture, 205(1), 37-56. https://doi.org/10.1007/s10704-017-0180-8

[5] Behnood, A., \& Gharehveran, M. M. (2019). Morphology, rheology, and physical properties of polymer-modified asphalt binders. European Polymer Journal, 112, 766-791. https://doi.org/10.1016/j.eurpolymj.2018.10.049

[6] Singh, B., \& Kumar, P. (2021). Investigating the performance of polymer and warm mix modified asphalt binders and mixtures. International Journal of Pavement Engineering,

1-15. https://doi.org/10.1080/10298436.2021.1915491

[7] Goli, A., Ziari, H., \& Amini, A. (2017). Influence of carbon nanotubes on performance properties and storage stability of SBS modified asphalt binders. Journal of Materials in Civil Engineering, 29(8), 04017070. https://doi.org10.1061/(ASCE)MT.1943-5533.0001910

[8] Al-Omari, A., Taamneh, M., \& Imam, R. (2021). The effects of adding Nano Clay and Nano Zinc Oxide on asphalt cement rheology. Journal of King Saud UniversityEngineering

Sciences. https://doi.org/10.1016/j.jksues.2021.03.010

[9] Habbouche, J., Hajj, E. Y., Sebaaly, P. E., \& Piratheepan, M. (2020). A critical review of high polymer-modified asphalt binders and mixtures. International Journal of Pavement Engineering, 21(6), https://doi.org/10.1080/10298436.2018.1503273

[10] Habbouche, J., Boz, I., Diefenderfer, B. K., Smith, B. C., \& Adel, S. H. (2021). State of the Practice for High PolymerModified Asphalt Binders and Mixtures. Transportation Research Record, 0361198121995190. https://doi.org/10.1177/0361198121995190

[11] Milad, A., Ahmeda, A. G., Taib, A. M., Rahmad, S., Solla, M., \& Yusoff, N. I. M. (2020). A review of the feasibility of using crumb rubber derived from end-of-life tire as asphalt binder modifier. Journal of Rubber Research, 1-14. https://doi.org/10.1007/s42464-020-00050-y

[12] Shah, P. M., \& Mir, M. S. (2020). Application of nanotechnology in pavement engineering: a review. Canadian Journal of Civil Engineering, 47(9), 1037-1045. https://doi.org/10.1139/cjce-2019-0395

[13] Badri, R. M., Sutanto, M., \& k Alobaidi, M. (2020). Investigating the rheological properties of asphalt binder incorporating different crumb rubber contents based on a response surface methodology. Journal of King Saud University-Engineering Sciences. https://doi.org/10.1016/j.jksues.2020.10.009

[14] Abed, Y. H., \& Al-Haddad, A. H. A. (2020). Temperature Susceptibility of Modified Asphalt Binders. In IOP Conference Series: Materials Science and Engineering, 671(1), $012121 . \quad$ IOP Publishing. https://doi.org/10.1088/1757-899X/671/1/012121

[15] Pouranian, M. R., Imaninasab, R., \& Shishehbor, M. (2020). The effect of temperature and stress level on the rutting performance of modified stone matrix asphalt. Road Materials and Pavement Design, 21(5), 1386-1398. https://doi.org/10.1080/14680629.2018.1546221

[16] Vamegh, M., \& Ameri, M. (2021). Rutting performance of road pavement asphalt binders modified by polymers. Proceedings of the Institution of Civil EngineersConstruction Materials, 174(4), 206-213. https://doi.org/10.1680/jcoma.17.00073
[17] Yao, T., Han, S., Men, C., Zhang, J., Luo, J., \& Li, Y. (2021). Performance evaluation of asphalt pavement groove-filled with polyurethane-rubber particle elastomer. Construction and Building Materials, 292, 123434. https://doi.org/10.1016/j.conbuildmat.2021.123434

[18] Saowapark, W., Jubsilp, C., \& Rimdusit, S. (2019). Natural rubber latex-modified asphalts for pavement application: effects of phosphoric acid and sulphur addition. Road Materials and Pavement Design, 20(1), 211-224. https://doi.org/10.1080/14680629.2017.1378117

[19] Zhang, J., Yao, Z., Yu, T., Liu, S., \& Jiang, H. (2019). Experimental evaluation of crumb rubber and polyethylene integrated modified asphalt mixture upon related properties. Road Materials and Pavement Design,20(6), https://doi.org/10.1080/14680629.2018.1447505

[20] Eltwati, A. S., Hossein, A., \& Nasr, D. (2020). Effect of Crumb Rubber Particles on the Properties of Asphalt. In ICACE 2019 ， 43-52. Springer, Singapore. https://doi.org/10.1007/978-981-15-1193-6_5

[21] Pouranian, M. R., Notani, M. A., Tabesh, M. T., Nazeri, B., \& Shishehbor, M. (2020). Rheological and environmental characteristics of crumb rubber asphalt binders containing non-foaming warm mix asphalt additives. Construction and Building Materials, 238, 117707. https://doi.org/10.1016/j.conbuildmat.2019.117707

[22] Abdelmagid, A. A., \& Feng, C. P. (2019). Laboratory evaluation of the effects of short-term aging on high temperature performance of asphalt binder modified with crumb rubber and rice husk ash. Petroleum Science and Technology, 37(13), 1557-1565. https://doi.org/10.1080/10916466.2019.1590409

[23] Huang, J., \& Wang, Q. A. (2021). Influence of crumb rubber particle sizes on rutting, low temperature cracking, fracture, and bond strength properties of asphalt binder. Materials and Structures, 54(2), 1-15. https://doi.org/10.1617/s11527-021-01647-4

[24] Jamrah, A. A., \& Kutay, M. E. (2020). A new rheological approach to evaluating the aged performance of Crumb Rubber Modified binders. International Journal of Pavement Engineering, 1-14. https://doi.org/10.1080/10298436.2020.1830090

[25] Mirzaiyan, D., Ameri, M., Amini, A., Sabouri, M., \& Norouzi, A. (2019). Evaluation of the performance and temperature susceptibility of gilsonite-and SBS-modified asphalt binders. Construction and Building Materials, 207, 679-692.

https://doi.org/10.1016/j.conbuildmat.2019.02.145

[26] Ameli, A., Norouzi, N., Khabbaz, E. H., \& Babagoli, R. (2020). Influence of anti stripping agents on performance of binders and asphalt mixtures containing Crumb Rubber and Styrene-Butadiene-Rubber. Construction and Building Materials, 261, 119880 https://doi.org/10.1016/j.conbuildmat.2020.119880

[27] Ameli, A., Pakshir, A. H., Babagoli, R., Habibpour, A., Norouzi, N., \& Davoudinezhad, S. (2021). The effects of gilsonite and crumb rubber on moisture damage resistance of stone matrix asphalt mixtures. Construction and Building Materials, 274, 122052. https://doi.org/10.1016/j.conbuildmat.2020.122052

[28] Amini, A., Ziari, H., Saadatjoo, S. A., Hashemifar, N. S., \& Goli, A. (2021). Rutting resistance, fatigue properties and temperature susceptibility of nano clay modified asphalt rubber binder. Construction and Building Materials, 267, 120946.

https://doi.org/10.1016/j.conbuildmat.2020.120946 
[29] Abdulrahman, S., Hainin, M. R., Satar, M. K. I. M., Hassan, N. A., \& Al Saffar, Z. H. (2020, April). Review on the potentials of natural rubber in bitumen modification. In IOP Conference Series: Earth and Environmental Science, 476(1), $012067 . \quad$ IOP Publishing. https://doi.org/10.1088/1755-1315/476/1/012067

[30] Liang, P., Liang, M., Fan, W., Zhang, Y., Qian, C., \& Ren, S. (2017). Improving thermo-rheological behavior and compatibility of SBR modified asphalt by addition of polyphosphoric acid (PPA). Construction and Building Materials, 139 ,

183-192. https://doi.org/10.1016/j.conbuildmat.2017.02.065

[31] Liu, G., Liang, Y., Chen, H., Wang, H., Komacka, J., \& Gu, X. (2019). Influence of the chemical composition and the morphology of crumb rubbers on the rheological and selfhealing properties of bitumen. Construction and Building Materials, 210, 555-563. https://doi.org/10.1016/j.conbuildmat.2019.03.205

[32] Mashaan, N. S., Chegenizadeh, A., Nikraz, H., \& Rezagholilou, A. (2021). Investigating the engineering properties of asphalt binder modified with waste plastic polymer. Ain Shams Engineering Journal, 12(2), 15691574. https://doi.org/10.1016/j.asej.2020.08.035

[33] Ahmad, A. F., Razali, A. R., \& Razelan, I. S. M. (2017, May). Utilization of polyethylene terephthalate (PET) in asphalt pavement: A review. In IOP Conference Series: Materials Science and Engineering , 203(1), 012004. IOP Publishing. https://doi.org/10.1088/1757-899X/203/1/012004

[34] Joohari, I. B., \& Giustozzi, F. (2020). Chemical and hightemperature rheological properties of recycled plasticspolymer modified hybrid bitumen. Journal of Cleaner Production 276 123064. https://doi.org/10.1016/j.jclepro.2020.123064

[35] Bensaada, A., Soudani, K., \& Haddadi, S. (2021). Effects of short-term aging on the physical and rheological properties of plastic waste-modified bitumen. Innovative Infrastructure Solutions, 6(3), 1-12. https://doi.org/10.1007/s41062-021-00471-7

[36] Bari, J., \& Witczak, M. W. (2007). New predictive models for viscosity and complex shear modulus of asphalt binders: for use with mechanistic-empirical pavement design guide. Transportation Research Record, 2001(1), 919. https://doi.org/10.3141\%2F2001-02

[37] ASTM-D36 (1998) Standard Test Method for Softening Point of Bitumen (Ring-and-Ball Apparatus), A.W. Drews, Editor. ASTM International: West Conshohocken, PA. p. 50-53. https://doi.org/10.1520/MNL10830M

[38] ASTM-D5 (1998) Standard Test Method for Penetration of Bituminous Materials, A.W. Drews, Editor. ASTM International: West Conshohocken, PA. p. 47-49. https://doi.org/10.1520/MNL10829M

[39] ASTM-D4402 (2015) Standard test method for viscosity determination of asphalt at elevated temperatures using a rotational viscometer. in American Society for Testing and Materials. West Conshohocken, PA.

[40] Hunter, R. N., Self, A., Read, J., \& Hobson, E. (2015). The shell bitumen handbook (p. 789). London, UK:: ICE Publishing.

[41] Galooyak, S. S., Dabir, B., Nazarbeygi, A. E., \& Moeini, A. (2010). Rheological properties and storage stability of bitumen/SBS/montmorillonite composites. Construction and building materials, 24(3), 300-307. https://doi.org/10.1016/j.conbuildmat.2009.08.032

[42] Ziari, H., Mirzababaei, P., \& Babagoli, R. (2016). Properties of bituminous mixtures modified with a nanoorganosilane additive. Petroleum Science and Technology,
34(4), 386-393. https://doi.org/10.1080/10916466.2015.1136948

[43] Roberts, F. L., Kandhal, P. S., Brown, E. R., Lee, D. Y., \& Kennedy, T. W. (1991). Hot mix asphalt materials, mixture design and construction.

[44] Rasmussen, R. O., Lytton, R. L., \& Chang, G. K. (2002). Method to predict temperature susceptibility of an asphalt binder. Journal of materials in civil engineering, 14(3), 246-252. https://doi.org/10.1061/(ASCE)08991561(2002)14:3(246)

[45] Zhang, D., Birgisson, B., Luo, X., \& Onifade, I. (2019). A new short-term aging model for asphalt binders based on rheological activation energy. Materials and Structures, 52(4), 1-22. https://doi.org/10.1617/s11527-019-1364-7

[46] Maze, M. (1996). Viscosity of EVA Polymer-Modified Bitumens: Modelling No. 5170 Section 5. In Euraspahlt \& Eurobitume Congress.

[47] Leng, Z., Padhan, R. K., \& Sreeram, A. (2018). Production of a sustainable paving material through chemical recycling of waste PET into crumb rubber modified asphalt. Journal of cleaner production, 180, 682-688. https://doi.org/10.1016/j.jclepro.2018.01.171

[48] Fethiza Ali, B., Soudani, K., \& Haddadi, S. (2020). Effect of waste plastic and crumb rubber on the thermal oxidative aging of modified bitumen. Road Materials and Pavement Design,

$1-12$ https://doi.org/10.1080/14680629.2020.1820893

[49] Salomon, D., \& Zhai, H. (2004). Asphalt binder flow activation energy and its significance for compaction effort. In Proceedings of 3rd Euroasphalt \& Eurobitume Congress (pp. 1754-1762).

[50] Salomon, D., \& Zhai, H. (2002). Ranking asphalt binders by activation energy for flow. Journal of Applied Asphalt Binder Technology, 2(2), 52-60. 